\title{
SUMMARY OF THE STATE OF THE ART: Risk Communication to the Public
}

\author{
Prepared by \\ Vicki M. Bier, Director \\ Center for Human Performance in Complex Systems \\ University of Wisconsin-Madison \\ Madison, Wisconsin
}

August 1999

NRC Contract No. 04-97-064

Project Manager, Isabelle Schoenfeld

Office of Nuclear Regulatory Research 


\section{Background ${ }^{1}$}

The advent of risk-informed regulation creates new challenges for risk communication, including how to explain the process of risk-informed regulation and effectively communicate risk-informed decisions to the general public. This summary of the state of the art on risk communication to the public was prepared as part of a task on risk communication in support of risk-informed regulation being performed under a cooperative agreement between the University of Wisconsin-Madison (UW) and the U.S. Nuclear Regulatory Commission (NRC). A similar summary of the state of the art on risk communication to decision-makers has also been prepared.

The database for this summary consists primarily of published literature in the areas of risk analysis and applied communications, supplemented by more specialized literature from fields such as experimental psychology and educational psychology. The summary draws on other products generated under this project (including a 1998 workshop on risk communication in support of risk-informed regulation and an annotated bibliography on risk communication for government practitioners), and also utilizes an earlier annotated bibliography by Fisher et al. (1995).

\section{Introduction}

Rowan (1991) has identified five possible goals of risk communication. They are: building trust in the communicator; raising awareness (e.g., of a potential hazard); educating; reaching agreement (e.g., on a particular strategy for cleaning up a hazardous waste site); and motivating action (e.g., encouraging people to practice safe sex or reduce the levels of radon in their homes). Because of this multiplicity of purposes, different strategies of risk communication may be appropriate for different goals. For example, simple, vivid risk communication messages are best for raising awareness (Rowan, 1991), while stakeholder participation methods are likely to be more appropriate for reaching agreement on a course of action. Even the measures of success may vary depending on the purpose of the risk communication effort. For example, if a program has succeeded in educating teenagers accurately about the risks of unsafe sex, but has not persuaded them to take protective actions, is it a success as an educational effort, or a failure from a motivational point of view?

The multiplicity of risk communication purposes and measures of success makes the process of needs assessment centrally important before actually undertaking a risk communication effort. Needs assessment is a series of questions to be answered in the process of planning a risk communication effort. It is intended to be fairly general-i.e., to help risk communicators think

\footnotetext{
1 This report was prepared as an account of work sponsored by an agency of the United States Government. Neither the United States Government nor any agency thereof, nor any employees, makes any warranty, express or implied, or assumes any legal or responsibility for any third party's use, or the results of such use, of any information, apparatus, product, or process disclosed in this report, or represents that its use by such third party would not infringe privately owned rights. The views expressed in this report are not necessarily those of the U.S. Nuclear Regulatory Commission. This report has not been published as a NUREG series publication.
} 
through the who, what, and why of their need to communicate about risk analysis results or riskinformed regulatory decisions, before designing specific risk communication messages. For example, Lundgren and McMakin (1998) note that the scope of a risk communication message may be constrained or dictated by legal requirements, institutional policies, and audience characteristics, all of which need to be understood. Without a thorough needs assessment (including audience analysis), risk communication efforts may suffer from "limited understanding of the interests, concerns, fears, values, priorities, and preferences of individual citizens and public groups," and therefore fail to provide "data addressing the specific fears and concerns of individual communities" (Covello et al., 1987).

In addition, any organization planning a risk communication effort needs to clarify whether the goal is to gain consensus on a course of action, or only to educate people. If the former, is the organization willing to share decision-making power with the stakeholders affected by a particular risk? If so, this is likely to facilitate the process of building trust and gaining agreement on a course of action. However, if legal requirements or predetermined organizational policies dictate a particular decision, then creating the appearance of stakeholder participation without a real voice in the ultimate decision will only serve to alienate people. Thus, Lundgren and McMakin (1998) warn, "don't promise what you can't deliver." If the goal of the risk communication effort is limited to informing people, without providing them input into the decision, this should be made clear up front. In such cases, stakeholder participation processes are not necessary, and the clarity of the explanation or message is more important than the opportunity for the audience to participate actively in the discussion. However, even in these cases, it is important for risk communicators to remember that communication is a two-way street, and therefore to listen and respond to audience concerns as they arise.

Because of the complexity of the issues involved, risk communication research has so far yielded few definitive empirical results, despite a voluminous literature. The field is, therefore, perhaps best characterized as an "art" rather than a science. As in many such areas, experienced risk communicators are often able to obtain better results than novices, and most experts are likely to offer similar recommendations on many issues (e.g., there is general agreement on the importance and value of stakeholder participation processes). However, much of the literature is either anecdotal or conjectural, and even experts have made predictions about the effectiveness of different risk communication strategies that later studies have not substantiated. Moreover, following the recommended "best practices" in the field is not enough to ensure the success of a risk communication effort, since many of the variables that influence success are not yet fully understood, and some are generally outside the control of the communicator.

Despite these limitations, much can be learned from reviewing the present state of the art in risk communication. The lack of definitive empirical evidence regarding many important questions about how to best structure risk communication messages and processes also makes it important to systematically pretest risk communication messages, methods, and approaches (see for example Lundgren and McMakin, 1998). Even approaches that worked well in one context or for one audience may not be successful in a different context or with a different type of audience. 
3. Empirical results regarding format of risk communication messages

A small but growing body of empirical work in risk communication and related fields has investigated the effects of different message formats. For example, in a study dealing with the risks of radon in homes, Johnson et al. (1988) studied the effectiveness of qualitative (i.e., verbal) versus quantitative (both verbal and numerical) formats. This study also compared a "command" approach (i.e., "emphasizing what the reader should do"; emphasis added) versus a "cajole" approach (i.e., "emphasizing what the reader may want to consider in reaching a decision"). Similarly, in a study of food safety, Fisher et al. $(1992,1994)$ tested the effectiveness of written (i.e., brochure) versus computer-mediated communication, and also investigated whether learning was enhanced by asking subjects to respond to a series of factual questions about the topic before reading the risk communication messages.

The Johnson study found that "the command-qualitative version increased learning," "the quantitative...booklets [led] to greater consistency between perceived and objective risk," and "the cajole-qualitative version had a positive effect on the likelihood of one's making an appropriate recommendation" to one's neighbor. Thus, no single presentation format was unequivocally best, and the preferred format appears to vary depending on whether the purpose of the risk communication effort is to educate, to affect risk perceptions, or to motivate people to take appropriate actions. Similarly, the Fisher study found no significant differences in learning between recipients of printed and computer-mediated risk communication messages; asking respondents to answer factual questions about the topic at hand before reading the informational materials also did not significantly increase learning. Hence, these studies have so far yielded little in the way of definitive results, both because of the small number of empirical studies in this area, but also because the existing studies have provided ambiguous or equivocal results. This underscores the importance of pilot testing risk communication messages before they are used, since general guidance on how to structure such messages is not yet available.

Studies reported in the literature have compared the effectiveness of verbal, numerical, and graphical methods of communicating probabilistic information. Interestingly, Gonzalez and Wallsten (1992) found that verbal presentation of probability information seemed to yield fewer "preference reversals" or inconsistencies on the part of experimental subjects than the use of numerical information. However, past studies on the correspondence between verbal and numerical presentations of probabilistic information have found large variability in how people translate probabilistic phrases (such as "highly unlikely") into numerical values, and these studies have generally not extended to probabilities less than $1 \%$. See for example BeythMarom (1982), Budescu and Wallsten (1985), Budescu et al. (1988), Gonzalez and Wallsten (1992), Hakel (1968), Lichtenstein and Newman (1967), Pepper (1981), Shiloh and Sagi (1989), Simpson (1944, 1963), and Stone and Johnson (1959). Survey articles by Budescu and Wallsten (1995), Clark (1990), and Wallsten and Budescu (1995) provide recent overviews of this literature. Thus, there does not appear to be any definitive guidance on how to translate numerical probabilities into lay language. 
Presentation formats may be particularly important in conveying small probabilities, since it is already known that people tend to overweight small probabilities in decision-making. See for example work by Ali (1977), Griffith (1949), Lichtenstein et al. (1978), Lopez Gomez (1990), Nogee and Lieberman (1960), Preston and Baratta (1948), and Sprowls (1953). Kaplan et al. (1986) found that graphical representations of extremely small side effect probabilities increased the probability that experimental subjects would state that they were willing to take a vaccine. This suggests that graphical portrayals of very small probabilities may reduce the tendency to overemphasize those probabilities in decision-making by effectively illustrating how small they really are. However, relatively little work has been done in this area.

\section{Empirical results regarding risk comparisons}

Another approach that seems intuitively appealing for communicating risks (especially for conveying the meaning of very small probabilities) is the use of risk comparisons. In fact, Roth et al. (1990) state: "A tempting way to describe the risks of hazardous technologies is by comparison with other, better known risks." Moreover, results by Shiloh and Sagi (1989) in the context of genetic counseling suggest that risk comparisons may help to reduce the tendency to overweight small probabilities. Unfortunately, the empirical literature indicates that it is difficult to identify suitable risk comparisons.

For example, a risk communication manual by Covello et al. (1988) describes 14 different categories of risk comparisons that have been used, ranging from "comparisons of the same risk at two different times" to "comparisons of unrelated risks." It then offers some hypotheses regarding the likely "acceptability" of these various types of comparisons to members of the general public. A subsequent empirical test by Roth et al. (1990) revealed that lay people rated "comparisons of risks across domains" (e.g., comparison of the risks of ethylene oxide with the risks of lightning) and "comparisons of occupational with environmental risks" favorably on their ability to help people "better understand the risk." Other favorably regarded risk comparisons included "comparisons of the same risk at two different times" (e.g., a few years ago vs. now) and "comparisons with other specific causes of the same disease, illness, or injury." Perhaps surprisingly, Roth's subjects found "comparisons with a standard" (e.g., comparisons of actual emissions with an EPA emissions standard) and "comparisons with different estimates of the same risk" difficult to understand.

Seemingly reasonable comparisons can even serve to increase the perceived risk of a particular hazard if there is distrust of the individual or organization making the comparison. For example, Freudenburg and Rursch (1994) found that explaining a risk of one in 1,000,000 as "less than the risk of smoking a couple dozen cigarettes" made experimental subjects less willing to accept a hypothetical hazardous waste incinerator than they were when the probabilistic information was presented without interpretation. The authors suggest that this may be because the company proposing the incinerator was viewed with suspicion, so a seemingly favorable risk comparison was seen as suspect if provided by a company representative-"Yeah, we've heard that before." 
Thus, predictions about which risk comparisons are likely to be effective communication devices may not be reliable, and inappropriate comparisons can have undesirable results. Moreover, the empirical results presented by Roth et al. may not provide reliable guidance on which types of risk comparisons are likely to be acceptable to members of the general public in any particular context, for a variety of reasons. First, the specific criteria they used (e.g., whether the comparisons are clear, reassuring, etc.) may not capture all aspects of public acceptability. Second, since Roth et al. tested only a single risk comparison of each type, the specific examples they tested may not have been good exemplars of the types of comparisons they were intended to represent.

Finally, as noted by Freudenburg and Rursch, the acceptability of risk comparisons may depend not only on the nature of the comparison itself, but also on the purpose for which it is being used and on the individual or organization making the comparison. Thus, a particular comparison may be considered highly acceptable when used by a university professor to foster student understanding of a particular environmental risk, but much less so when used by a company trying to gain public approval for siting of a hazardous facility. Slovic et al. (1990) note that "comparisons of unrelated risks are frequently advanced as a means for setting priorities and determining which risks are acceptable," even though such risk comparisons usually fail to capture the wide variety of issues that influence judgments of risk acceptability.

\section{Empirical results regarding differences among audiences}

In recent years, researchers have begun to identify significant differences in risk perception among different audiences, which may be important to take into consideration when crafting risk communication messages. In reviewing this literature, Slovic (1997) notes that "men tend to judge risks as smaller and less problematic than do women." More specifically, "white males produced risk-perception ratings that were consistently much lower" than ratings of the same hazards given by white females or nonwhites; this has sometimes been dubbed the "white-male effect." According to work by Flynn et al. (1994), those white males with the lowest risk rankings tended to be well educated, well off financially, and relatively conservative politically.

The influence of more general "worldviews" (in particular, fatalism, willingness to defer to experts, individualism, egalitarianism, and support for the use of advanced technology) on perceptions of risk is also summarized; such worldviews have been found to correlate strongly with risk perceptions. For example, in summarizing work by Peters and Slovic (1996), Slovic (1997) states that: "Egalitarians prefer a world in which power and wealth are more evenly distributed...and tended to be strongly antinuclear; persons endorsing fatalist, hierarchist, and individualistic views tended to be pronuclear."

In a study of risk communication regarding radon in homes, Johnson et al. (1988) also found individual differences in people's understanding of risk communication messages (as opposed to their perceptions of those risks). For example, people with higher radon levels in their homes appeared to learn more from risk communication messages, perhaps due to greater motivation. In addition, on a quiz used to judge understanding of the risk communications materials, "older 
people had fewer correct answers...People with more education and prior awareness of radon performed better." These results suggest that more effort may be needed in crafting risk communications for particular audiences, who for whatever reason (e.g., age, lack of motivation or awareness, lack of education) may have a hard time learning new material or understanding highly technical information.

Socioeconomic differences can also be important in this regard. For example, Yosie and Herbst (1998) note that "people with lower incomes or poor English...skills" may have difficulty participating effectively in the process of risk communication. This is problematic since, as noted by the environmental justice movement, "hazardous waste facilities and other industries perceived to be 'risky' were apparently more often being [s]ited in minority or low-income areas" (Lundgren and McMakin, 1998). Thus, Kasperson et al. (1992) caution that "those most affected by the risk may be the least likely to participate in the process and may possess the fewest resources... Special attention is required, therefore, to ensure that their concerns are fully addressed."

Finally, individuals and groups vary in the extent to which they hold extreme or "fringe" positions vs. middle-of-the-road views that are widely shared within a given community. Heath (1995) cites an example of a company that "made a grave mistake when it did not distinguish the powerful from the fringe groups and try to work with the former to ascertain and meet community expectations." As pointed out in that case study, failing to address the concerns of critics in an open and responsible manner (even critics that hold relatively extreme positions) can antagonize more powerful groups; e.g., well respected environmental organizations, opinionmakers such as journalists, and middle-of-the-road members of the public "concerned about health." Therefore, in analyzing the audience for a risk communication process or message (particularly when the aim is to achieve consensus regarding a course of action), it is helpful to identify the likely levels of support from various groups. While it may be impossible to gain the agreement of all interest groups, carrying out risk communication efforts in a manner that indicates respect for people's concerns can help to maintain trust and credibility, and thereby increase community support for proposed projects (Heath, 1995). By contrast, organizations that "underestimate or dismiss community concerns about environmental hazards...stand a good chance of becoming distrusted and having projects defeated or indefinitely delayed" due to community opposition (Heath, 1995).

6. Empirical results regarding mental models

Many approaches reviewed above (e.g., the different categories of risk comparisons, or the use of verbal, numerical, or graphical formats for presenting risk information) appear to have little systematic impact on the effectiveness of the resulting risk communication. Thus, simply finding the "best" possible format or the "best" risk comparison may not be sufficient to ensure that the message is actually effective for its intended audience(s). Moreover, the evidence regarding individual differences in both attitudes and knowledge about risks suggests that there may be no "one-size-fits-all" approach. Thus, it is important to understand people's mental models (i.e., "how people understand and view various phenomena"; Lundgren and McMakin, 
1998) in order to craft effective risk communication messages and help them understand complex or unfamiliar phenomena.

Therefore, Rowan $(1991,1992,1994)$ advocates use of "a problem-solving approach to risk communication," in which the first task is to identify the most important problem (or problems) to be overcome by the risk communication message. The message can then be designed with those specific challenges in mind. Without such a problem-solving approach, it may not be clear which information to include in a risk communication message. As noted by Fischhoff (1998), "All too often...it is hard to know why particular facts were chosen for risk communications...Commonly known facts may be repeated, while potentially useful ones are presented without necessary context."

When the purpose of risk communication is primarily to enhance understanding, Rowan identifies three possible barriers to comprehension: the lack of familiarity with a particular concept or term; the lack of a mental model relevant to the subject at hand; and the existence of misconceptions. An explanation designed to clarify the meaning of a particular term should ideally include not only a definition, but also a variety of examples illustrating what the term does and does not mean. The inclusion of both examples and "nonexamples (i.e., instances one might think are examples but are not)" to illustrate a particular concept can help people distinguish "its critical (always present) features from its variable (frequently present but not inevitable) features" (Rowan, 1991). In particular, providing non-examples and distinguishing critical from variable features can help to prevent misconceptions, by ensuring that people do not mistakenly generalize from one or two examples and assume that all instances of a term or concept share the same characteristics as those examples. See Tennyson and Cocchiarella (1986) for a more detailed explanation of this approach and a review of the literature in this area.

Another challenge commonly encountered by risk communication is the complexity of the subject matter to be conveyed; this is also a problem in science education and related areas. In such situations, research indicates that it is often helpful to structure messages using a "concept map" or "mental model" of the phenomenon being described (Rowan, 1991, 1992; Shymansky and Kyle, 1988). For example, Shymansky and Kyle cite references from science education showing that the use of concept maps (i.e., "spatial representations...for each concept" that show how various ideas are related to each other) leads to improved learning, and also an improved ability to remember what was learned. Other simple tactics that have been demonstrated to be effective for explaining complex phenomena are the use of outlines (Krug et al., 1989), headings (Krug et al., 1989; Loman and Mayer, 1983), introductory overviews (Ausubel, 1960; Loman and Mayer, 1983), and summaries to emphasize key concepts. Armbruster (1984) reviews the use of tactics such as titles and subtitles, introductory overviews, and topic sentences in textbooks, and provides good and bad (i.e., "inconsiderate") examples of each. See also Reder (1985) for additional discussions of these tactics within the area of educational psychology, and Atman et al. (1994) and Rowan (1994) for discussions of these tactics in the context of risk communication. 
There has recently been a great deal of interest in the use of mental models and related ideas in communication regarding environmental hazards. In particular, mental models have been developed and evaluated for hazards such as radon (Atman et al., 1994; Bostrom et al., 1994a), electromagnetic fields (MacGregor et al., 1994), global climate change (Bostrom et al., 1994b; Read et al., 1994), and space uses of nuclear power (Maharik and Fischhoff, 1992, 1993). Empirical results from those studies suggest that risk communication messages based on mental models are more effective at conveying both general knowledge and also information about risk reduction strategies (Bostrom et al., 1994a; Maharik and Fischhoff, 1993). Effects on risk perceptions (rather than knowledge) are mixed. A brochure on nuclear power in space based on audience mental models was as effective at inducing favorable attitudes to space nuclear power as a previous NASA-designed brochure (Maharik and Fischhoff, 1993), although the mental models brochure was designed to be neutral while the NASA brochure was promotional in tone. A similar mental models brochure dealing with electromagnetic fields (EMF), on the other hand, increased recipients' concerns about this possible hazard, despite emphasizing the weak and speculative nature of the evidence for health effects caused by EMF (MacGregor et al., 1994). The authors note that "the reasons for increased perceptions of risk subsequent to reading the brochure are not fully apparent," but speculate that mentioning the possible risks of electromagnetic fields may make those hazards "more memorable, more imaginable, and more probable" in people's minds.

As noted above, the intended audience for a risk communication message may already hold misconceptions about the phenomenon at hand, and hence may find the information being conveyed implausible or difficult to understand. Such misconceptions may include mistaken theories about the specific hazard being discussed (e.g., a belief that ozone depletion is the cause of global warming, or that nuclear plants can explode), and also general heuristics or rules of thumb (e.g., a belief that more testing is always better). Research indicates that "people must have naive views...thoroughly disproved before they can fully understand and appreciate an explanation of initially implausible expert notions" (Rowan, 1991). For example, Shymansky and Kyle (1988) cite several studies providing empirical evidence that "the use of instructional strategies...especially designed to focus the students' attention on misconceptions" improves student learning. Thus, when a significant misconception exists, it is important to address it explicitly (by pointing out why the misconception may seem intuitively plausible, why it is flawed, and why the expert point of view does a better job of explaining the known facts), rather than merely presenting the correct information. Therefore, Rowan (1991) notes, "analogies are ineffective tools for explaining counter-intuitive ideas unless they are preceded by an account acknowledging the apparent legitimacy of the implicit erroneous view and a demonstration of its inadequacy."

Based on the above results, assessing what your intended audience already knows or believes about a particular issue is clearly important in designing effective risk communication messages. There are many ways of doing this, including convening focus groups, consulting with public information officers or others who regularly interact with members of the general public, and relying on published information. For example, in the area of nuclear power, Freudenburg and Baxter (1984) document the effect of the Three Mile Island (TMI) accident on attitudes toward 
nuclear power in communities with nuclear power plants. In particular, they note that "No known pre-TMI host community survey showed more than 33 percent opposition [to nuclear power]; no known post-TMI survey has shown less than 50 percent opposition." Thus, they conclude that even communities that already contain nuclear power plants are likely "to oppose the construction of new nuclear power facilities." Rosa and Freudenburg (1993) provide a more general overview of attitudes toward nuclear power over time, with specific emphasis on the relationship between attitudes to nuclear power and attitudes to nuclear waste. In particular, they note that "Rather than showing any tendency to rebound toward earlier levels of favorability, public attitudes toward nuclear power appear to have become durably negative" since the TMI accident. They also cite evidence suggesting that "it may prove to be even more difficult to find acceptance for a nuclear repository" than a nuclear power plant. Finally, Waltar (1995) addresses a number of common concerns that limit public acceptance of nuclear energy, including concerns about radiation risks, reactor safety, nuclear waste disposal, and proliferation and terrorism. In accord with the recommendations of Rowan, he begins each section by describing an area of concern (e.g., concerns that radiation is not well understood by scientists, or that nuclear waste cannot be stored safely), and then explains why he believes those concerns are inaccurate or overstated. Similarly, the anthology by Dunlap et al. (1993) provides a number of useful references in the area of nuclear waste.

More recently, researchers have begun to develop so-called "constructivist" approaches to surveys, as an alternative to more traditional polling techniques to elicit attitudes about complex problems (see for example Flynn, 1996; Gregory et al., 1997). The intent of constructivist survey methods is to help people think through the questions they are being asked to address, and in so doing to "construct" their values, beliefs, and preferences, rather than to expect respondents to have coherent views on the subject prior to administration of the survey. While still not widely used, there is evidence suggesting that these approaches can provide more detailed information on the reasons that people hold particular beliefs. For example, an application of the proposed method to attitudes about forest management among residents of Ontario, Canada, identified five groups with significantly different attitudes (Gregory et al., 1997). Opinions covered a wide range of viewpoints, from those who distrusted the ability of forest management professionals to make reasonable decisions given the complexity of the problem (and therefore would prefer that no action be taken), to those who supported aerial spraying of herbicides. Because the method is still in the research stage, there is little empirical evidence on whether opinions elicited through constructivist surveys will be more stable (i.e., less heavily influenced by minor changes in question wording) than results of traditional surveys. However, the greater detail available on the reasons for particular beliefs may, nonetheless, be helpful in designing effective risk communication messages.

\section{Credibility and trust in risk communication}

According to Kasperson et al. (1992), "A broad-based loss of trust in the leaders of major social institutions and in the institutions themselves has occurred over the past three decades"

[emphasis in original]. The reasons for this general societal change are not well understood, but may include "the Vietnam War, the revelations of environmental degradation in the late 1960s 
and 1970 s, social protest, the Watergate scandal, and the energy crises and economic recessions of the 1970s." Thus, even in the absence of a past record of accidents or misdeeds, government and industry risk communicators face difficult challenges today.

This general loss of trust may also be exacerbated in particular contexts. For example, Freudenburg and Baxter (1984) argue that the Three Mile Island accident in 1979 was responsible for a significant increase in opposition to nuclear power. Similarly, public distrust in the U.S. Department of Energy (DOE) may be exacerbated by perceived "mismanagement of wastes at the nation's military weapons facilities operated by DOE" (Slovic et al., 1993; see also National Academy of Sciences, 1989).

Unfortunately, "trust is easier to destroy than to create" (Slovic, 1997). For example, recent empirical research suggests that "negative (trust-destroying) events carry much greater weight than positive events" (Slovic, 1993). Therefore, Kasperson et al. (1992) state that "Attempts to communicate about controversial risks...predicated upon well-intentioned efforts to regain social trust are, in our view, naïve at best and self-defeating at worst." Rather, they argue that risk communication methods and decision-making processes should be explicitly designed to function effectively in situations of distrust. Risk communication processes for situations of distrust can involve several strategies.

First, it is important to recognize that when an audience has serious concerns or negative impressions, one must begin by listening to them, before giving them information (e.g., Rowan, 1994). Attempting to convey new information before understanding which concerns are important to one's audience may suggest to them that those concerns are not being taken seriously, or are being dismissed as misguided. After one has acknowledged that people's concerns are important and based on valid or understandable motivations, they may be more willing to listen to new information and other points of view.

In situations of distrust, it may be constructive to create mechanisms by which concerned individuals can monitor a potentially hazardous situation for themselves. For example, Heath (1995) discusses the case of a chemical plant that adopted an "open-door policy," providing public access to all of the permits and "performance reports the company files with regulatory agencies" in a separate building located near the plant entrance. According to Heath, "When the building was first opened, it attracted a steady stream of concerned citizens. Now it rarely has a visitor," suggesting that the company's open-door policy (presumably combined with a good track record of performance) acted over time to create trust. The risk communication manual developed by Hance et al. (1988) emphasizes the importance of credibility and responsiveness in building trust, and gives excellent recommendations for dealing with situations of low trust. For example, the authors recommend that in situations of distrust, risk communicators "acknowledge the lack of trust..., indicate what steps you plan to take to prevent the trust-eroding actions from happening again..., ask those who distrust you what they feel would make them more likely to trust you [and] ...implement their suggestions, [and] try to reduce the need for trust by sharing information and involving the public in developing solutions to the risk problem" (emphasis in original). 
Perhaps the ultimate solution to situations of distrust is "the sharing of power, that is the empowerment of risk bearers, in the management of the risk or the facility" (Kasperson et al., 1992). With direct stakeholder participation in the process of environmental decision-making, stakeholders no longer need to rely on trust in senior decision-makers or their institutions, since they will themselves be decision-makers and will be able to observe and influence virtually all aspects of the process. Allowing stakeholders to participate in the decision-making process avoids "forcing cognitively involved members of the community to a confrontational stance" (Heath, 1995), which is often the result of more adversarial mechanisms such as public hearings. This approach is widely recommended today (see for example Kunreuther et al., 1996; Slovic, 1997), and is discussed in detail in the next section.

\section{Stakeholder participation processes}

The idea of stakeholder participation has its roots in the growth of alternative dispute resolution techniques in the 1970's and 1980's (see for example Bingham, 1986; Susskind and Cruikshank, 1987). However, stakeholder participation can take on many different forms, not limited to mediated dispute resolution, negotiation, and arbitration. Renn et al. (1995) provide an excellent overview of the variety of models available for public participation, including (among others) citizen advisory committees (CAC), Citizens Juries, regulatory negotiating committees, and mediation.

Rosener (1978) defines CACs as encompassing "several techniques in which relatively small group of citizens...are called together to represent ideas and attitudes of various groups and/or communities." By contrast, Crosby (1995) defines a Citizens Jury as "a group of randomly selected people.... who are paid to learn about and discuss.... specific public policy issue and make public their conclusions." Thus, unlike most CAC participants, members of Citizens Juries are generally selected at random and paid for their time. In addition, they are generally asked to respond to a well-defined "charge," rather than to express their views on a wide range of related issues. While versions of this approach (e.g., "science courts") have been proposed by others, the term "Citizens Jury" refers to a specific implementation of this idea developed by the Jefferson Center (of Minneapolis, Minnesota), which was founded in 1974 "to improve democracy without taking policy stands" (Crosby, 1995). Fiorino (1995) states that "regulatory negotiation brings together the representatives of different interests in an effort to agree on the content and often the language of regulations"; see Pritzker and Dalton (1995) for a more detailed discussion and examples involving the NRC, the EPA, the DOE, and other agencies. Finally, Cormick (1987) states that "Mediation is a voluntary process in which those involved in a dispute jointly explore and reconcile their differences"; the role of the mediator is simply "to assist the parties in settling their own differences."

The wide range of such models makes clear that there are many different forms of public participation. However, the use of citizen advisory committees is perhaps the most common approach in practice today, and is widely used by government agencies such as the Department of Defense, the Department of Energy, and the Environmental Protection Agency, as well as some private companies. The "Keystone report" (Federal Facilities Environmental Restoration 
Dialogue Committee, 1993) strongly recommends the creation of citizen advisory committees or "site-specific advisory boards" to improve the process of decision-making with regard to environmental restoration at the thousands of federal facilities around the country. Heath (1995) and Yosie and Herbst (1998) provide examples involving the chemical industry.

Unfortunately, there is little empirical evidence about how to structure stakeholder participation processes, or even which processes are most appropriate for which situations, although Renn et al. (1995) discuss the strengths and weaknesses of different approaches and the types of problems to which each method is best suited. Much of the research in this area has been qualitative and/or anecdotal (e.g., evaluations of a specific stakeholder process, rather than comparisons of multiple processes). Also, the wide variety of approaches taken to stakeholder participation makes it difficult to identify which differences are responsible for an observed difference in outcomes. For example, Lynn and Busenbert (1995) review 14 empirical studies of CACs, but note that the wide diversity in the designs of CACs and the limited number of empirical studies to date make it difficult to draw definitive conclusions. They recommend further research about "membership selection processes, the role of facilitators, the methods by which agendas are set..., the role of independent experts, methods by which a CAC can be held accountable to the public, methods of feedback from sponsor to CAC, and the purpose of CACs." Similarly, Yosie and Herbst (1998) note that "measuring stakeholder processes and results" is one of the keys to achieving greater use of stakeholder participation in the future. Finally, there is not yet agreement on the appropriate measures of success for stakeholder participation processes. For example, is a process successful if the parties involved gain "improved understanding of other stakeholders' viewpoints and interests, greater access to information, and...working relationships and trust," or does it need to result in "an agreement for solving a specific problem" (Yosie and Herbst, 1998)?

Despite the lack of definitive empirical results regarding stakeholder participation processes, a few general rules of thumb are broadly accepted. First, an organization should not attempt stakeholder participation without a true commitment to the process. If the organization with responsibility for making the ultimate decision is not actually willing to share decision-making power with the stakeholders affected by a particular risk, going through the motions of stakeholder participation will simply "increase hostility in the audience" (Lundgren and McMakin, 1998). Similarly, Yosie and Herbst (1998) note: "Convenors that establish a stakeholder process to generate some form of external validation for decisions they have internally resolved risk a serious erosion of their credibility and their ability to implement the decision." Thus, Lundgren and McMakin (1998) emphasize the importance of clarifying the audience's role to all concerned early in the process. More specifically, Yosie and Herbst (1998) distinguish between "decisional," "consultative," and "informational" processes. In other words, stakeholders can be enfranchised to participate in actual decision-making, "provide input on policy choices" (to be taken under advisement by the actual decision-makers), or merely provide specific narrowly defined types of information for use in the decision process.

Also, as with any risk communication effort, a needs assessment is a critical part of the planning process for stakeholder participation. Kasperson et al. (1992) point out that "The need to know 
cannot be defined solely by the expert or the communicator," but rather requires "two-way exchange of information to elicit what various publics believe they need and want to know." They also note that issues of concern to the public may not be limited to risk.

Finally, the success of any stakeholder participation process depends not only on how well the process is designed, planned, and implemented, but also on a host of external factors. For example, Yosie and Herbst (1998) note that "Some issues may not evoke sufficient public interest or concern to merit a stakeholder process"; if the affected community is apathetic about a particular risk, it may be difficult to get people to commit "the tremendous amount of time needed for negotiations." In addition, "excessive polarization among interests" can interfere with successful implementation of stakeholder participation processes. Even the best-managed process may be unable to achieve consensus on deeply divisive issues. In particular, Yosie and Herbst (1998) point out that people are unlikely to compromise on issues that are perceived to be a matter of basic rights or values (e.g., civil rights, beliefs about abortion). However, they may be more willing to negotiate on issues that affect their economic or other interests, where creative use of tradeoffs can sometimes achieve "mutually satisfactory outcomes."

\section{Conclusions}

Some key conclusions from this review of the state of the art in risk communication are presented below:

\section{Planning risk communication efforts}

The planning phase of a risk communication effort should involve determining:

1) Legal requirements or organizational policies that constrain the design of the risk communication message and/or format

2) The purpose of the risk communication; for example:

Raising awareness of a hazard (Example: alerting medical professionals to possible hazards involved in radiation therapy)

Educating people

(Example: designing a web site to answer frequently asked questions about nuclear power)

Motivating people to take action

(Example: encouraging people to reduce the levels of radon in their homes)

Reaching agreement on a controversial issue

(Example: deciding whether to approve siting of a dry cask storage facility for nuclear waste) 
Obtaining people's trust

(Example: providing evidence that a particular facility or industry has operated safely) 
3) Different risk communication strategies are appropriate for different purposes. Select a strategy that is appropriate for the purpose at hand; for example:

Simple, vivid messages to raise awareness of a hazard

Explanatory tools such as diagrams, outlines, and analogies to educate people

Techniques of persuasion to motivate people to action

Stakeholder participation processes to reach agreement on controversial issues

Mechanisms by which people can monitor potentially hazardous situations in order to build trust

4) The characteristics of the audience(s) for the risk communication; for example:

The audience's level of knowledge and education

The audience's mental models, attitudes, and beliefs about the issue at hand

The audience's level of receptivity and openness to the ideas being communicated

The audience's concerns about the issue

5) Sources of audience information include focus groups, surveys, public information officers, and articles and books describing the audience's views.

Designing risk communication messages

View risk communication as an opportunity to demonstrate trustworthiness and an open, responsible, and caring attitude.

Listen to audience concerns before attempting to impart new information.

Use risk comparisons with caution:

1) Consider presenting comparisons of the same risk at different times (e.g., a few years ago vs. now), comparisons with other causes of the same disease or injury, and comparisons with unrelated risks, such as the risk of lightning.

2) Avoid comparisons with risks that are generally viewed as trivial, such as the risk of eating a few tablespoons of peanut butter. 
3) Pilot test risk communication messages (especially risk comparisons) on a limited basis before using them more widely, to ensure that they are easily understood and not misinterpreted. This is particularly important in situations of distrust.

Features of risk information that may pose challenges to audience comprehension, and possible strategies for dealing with those challenges, include:

1) Use of small probabilities

Consider using graphical representations to illustrate how small a probability actually is.

2) Use of unfamiliar terms, or terms with unfamiliar meanings (Examples: "radionuclides," radioactive "sources," the "moderator" in a reactor)

Give examples illustrating both what a term means and what it does not mean, to ensure that audience members understand the definition and can apply it correctly.

3) Explanations of complex phenomena

(Examples: radioactive decay, radioactive deposition, safety system design and operation)

Make use of explanatory tools such as diagrams, outlines, and analogies to ensure that audience members develop accurate mental models of the phenomenon.

4) Audience misconceptions or incorrect intuitions

Acknowledge that the audience's misconception or intuition is plausible

(Example: "since testing is a good thing, it is natural to believe that more testing is always better")

Point out why the audience's view is inaccurate or incomplete (Example: "testing effort is sometimes wasted on components that are not very important to risk")

Present a correct explanation, and show why it avoids the flaws or weaknesses of the audience's original viewpoint (Example: "doing better at focusing testing efforts on the components that are most important to risk can improve safety while reducing the total testing effort") 


\section{Stakeholder participation}

Some strategies to consider for enhancing stakeholder participation include:

1) Ensuring that there is a true commitment to the process before undertaking stakeholder participation

2) Clarifying the scope and purposes of any stakeholder participation (e.g., education, consultation, etc.) to all participants

3) Clarifying whether participants will actually have a voice in the final decision. This is typically the case in Citizens Juries and regulatory negotiating committees, but may not always be true in some other types of stakeholder participation processes.

References

M. M. Ali, "Probability and Utility Estimates for Racetrack Bettors," Journal of Political Economy, Vol. 85, 1977, pp. 803-815.

B. B. Armbruster, "The Problem of 'Inconsiderate Text'," in G. G. Duffy, L. R. Roehler, and J. Mason (editors), Comprehension Instruction: Perspectives and Suggestions, New York: Longman, 1984.

C. J. Atman, A. Bostrom, B. Fischhoff, and M. G. Morgan, "Designing Risk Communications: Completing and Correcting Mental Models of Hazardous Processes, Part I," Risk Analysis, Vol. 14, 1994, pp. 779-788.

D. P. Ausubel, "The Use of Advance Organizers in the Learning and Retention of Meaningful Verbal Material," Journal of Educational Psychology, Vol. 51, 1960, pp. 267-272.

R. Beyth-Marom, "How Probable is Probable? Numerical Translation of Verbal Probability Expressions," Journal of Forecasting, Vol. 1, 1982, pp. 257-269.

G. Bingham, Resolving Environmental Disputes: A Decade of Experience. Washington, D.C.: The Conservation Foundation, 1986.

A. Bostrom, C. J. Atman, B. Fischhoff, and M. G. Morgan, "Evaluating Risk Communications: Completing and Correcting Mental Models of Hazardous Processes, Part II," Risk Analysis, Vol. 14, 1994a, pp. 789-798.

A. Bostrom, M. G. Morgan, B. Fischhoff, and D. Read, "What Do People Know About Global Climate Change? Part 1: Mental Models," Risk Analysis, Vol. 14, 1994b, pp. 959-970. 
D. V. Budescu and T. S. Wallsten, "Consistency in Interpretation of Probabilistic Phrases," Organizational Behavior and Human Decision Processes, Vol. 36, 1985, pp. 391-405.

D. V. Budescu and T. S. Wallsten, "Processing Linguistic Probabilities: General Principles and Empirical Evidence," in J. Busemeyer, D. L. Medin, and R. Hastie (editors), Decision Making from a Cognitive Perspective, San Diego: Academic Press, 1995.

D. V. Budescu, S. Weinberg, and T. S. Wallsten, "Decisions Based on Numerically and Verbally Expressed Uncertainties," Journal of Experimental Psychology: Human Perception and Performance, Vol. 14, 1988, pp. 281-294.

D. A. Clark, "Verbal Uncertainty Expressions: A Review of Two Decades of Research," Current Psychology: Research and Reviews, Vol. 9, pp. 203-235.

G. W. Cormick, "The Myth, the Reality, and the Future of Environmental Mediation," in R. W. Lake (editor), Resolving Locational Conflict, New Brunswick (New Jersey): Rutgers Center for Urban Policy Research, 1987.

V. T. Covello, D. von Winterfeldt, and P. Slovic, "Communicating Scientific Information about Health and Environmental Risks: Problems and Opportunities from a Social and Behavioral Perspective," in J. C. Davies, V. T. Covello, and F. W. Allen (editors), Risk Communication, Washington, D.C.: Conservation Foundation, 1987.

V. T. Covello, P. M. Sandman, and P. Slovic, Risk Communication, Risk Statistics, and Risk Comparisons: A Manual for Plant Managers, Washington, D.C.: Chemical Manufacturers Association, 1988.

N. Crosby, "Citizens Juries: One Solution for Difficult Environmental Questions," in O. Renn, T. Webler, and P. Wiedemann (editors), Fairness and Competence in Citizen Participation: Evaluting Models for Environmental Discourse, Dordrecht (The Netherlands): Kluwer, 1995.

R. E. Dunlap, M. E. Kraft, and E. A. Rosa (editors), Public Reactions to Nuclear Waste, Durham (North Carolina): Duke University Press, 1993.

Federal Facilities Environmental Restoration Dialogue Committee. Interim Report of the Federal Facilities Restoration Dialogue Committee: Recommendations For Improving The Federal Facilities Environmental Restoration Decision-Making and Priority-Setting Processes, Washington, DC: U.S. Environmental Protection Agency, 1993.

D. Fiorino, "Regulatory Negotiation as a Form of Public Participation," in O. Renn, T. Webler, and P. Wiedemann (editors), Faimess and Competence in Citizen Participation: Evaluting Models for Environmental Discourse, Dordrecht (The Netherlands): Kluwer, 1995. 
B. Fischhoff, "Communicate unto Others...," Reliability Engineering and System Safety, Vol. 59, 1998, pp. 63-72.

A. Fisher, R. King, W. Hewitt, D. J. Epp, K. Finley, J. L. Brown, and A. N. Maretzki, Understanding Food Safety Policy Issues-Report on Model Materials, University Park, PA: Department of Agricultural Economics and Rural Sociology, Pennsylvania State University, 1992.

A. Fisher, R. King, D. J. Epp, J. Lynne Brown, and A. N. Maretzki, "Evaluating Alternatives for Communicating about Food Risk," Journal of Applied Communications, Vol. 78, No. 2, 1994, pp. 1-11.

A. Fisher, S. Emani, and M. Zint, "Risk Communication for Industry Practitioners: An Annotated Bibliography," Washington, D.C.: Society for Risk Analysis, 1995.

J. Flynn, "Constructing and Reconstructing Respondent Attitudes During a Telephone Survey," American Statistical Association 1996 Proceedings of the Section on Survey Research Methods, Vol. 2, pp. 895-899, Alexandria (Virginia): American Statistical Association, 1996.

J. Flynn, P. Slovic, and C. K. Merta, "Gender, Race, and Perception of Environmental Health Risks," Risk Analysis, Vol. 14, 1994, pp. 1101-1108.

W. R. Freudenburg and R. K. Baxter, "Host Community Attitudes toward Nuclear Power Plants: A Reassessment," Social Science Quarterly, Vol. 65, 1984, pp. 1129-1136.

W. R. Freudenburg and J. A. Rursch, "The Risks of 'Putting the Numbers in Context': A Cautionary Tale," Risk Analysis, Vol. 14, 1994, pp. 949-958.

C. C. Gonzalez and T. S. Wallsten, "The Effects of Communication Mode on Preference Reversal and Decision Quality," Journal of Experimental Psychology: Learning, Memory, and Cognition, 1992.

R. Gregory, J. Flynn, S. M. Johnson, T. A. Satterfield, P. Slovic, and R. Wagner, "DecisionPathway Surveys: A Tool for Resource Managers," Land Economics, Vol. 73, 1997, pp. 240254.

R. M. Griffith, "Odds Adjustments by American Horse Race Bettors," American Journal of Psychology, Vol. 62, 1949, pp. 290-294.

M. Hakel, "How Often Is Often?," American Psychologist, Vol. 23, 1968, pp. 533-534.

B. J. Hance, C. Chess, and P. M. Sandman, Improving Dialogue with Communities: A Risk Communication Manual for Government, Trenton (New Jersey): New Jersey Department of Environmental Protection, 1988. 
R. L. Heath, "Corporate Environmental Risk Communication: Cases and Practices Along the Texas Gulf Coast," Communication Yearbook, Vol. 18, 1995, pp. 255-277.

R. Johnson, A. Fisher, K. Smith, and W. H. Desvouges, "Informed Choice or Regulated Risk? Lessons from a Study in Radon Risk Communication," Environment, Vol. 30, No. 4, 1988, pp. 12-15 and 30-35.

R. Kaplan, B. Hammel, and L. Schimmel, "Patient Information Processing and the Decision to Accept Treatment," Journal of Social Behavior and Personality, Vol. 1, 1986, pp. 113-120.

R. E. Kasperson, D. Golding, and S. Tuler, "Social Distrust as a Factor in Siting Hazardous Facilities and Communicating Risks," Journal of Social Issues, Vol. 48, No. 4, 1992, pp. 161178.

D. Krug, B. George, S. A. Hannon, and J. A. Glover, "The Effect of Outlines and Headings on Readers' Recall of Text," Contemporary Educational Psychology, Vol. 14, 1989, pp. 111-123.

H. Kunreuther, P. Slovic, and D. MacGregor, "Risk Perception and Trust: Challenges for Facility Siting," Risk: Health, Safety and the Environment, Vol. 7, 1996, pp. 109-118.

S. Lichtenstein and J. R. Newman, "Empirical Scaling of Common Verbal Phrases Associated with Numerical Probabilities," Psychonomic Sciences, Vol. 9, 1967, pp. 563-564.

S. Lichtenstein, P. Slovic, B. Fischhoff, M. Layman, and B. Combs, "Judged Frequency of Lethal Events," Journal of Experimental Psychology: Human Learning and Memory, Vol. 4, 1978, pp. 551-578.

N. L. Loman and R. E. Mayer, "Signaling Techniques That Increase the Understandability of Expository Prose," Journal of Educational Psychology, Vol. 75, 1983, pp. 402-412.

U. A. Lopez Gomez, "Communicating Very Low Probability Events," doctoral dissertation, Department of Engineering and Public Policy, Carnegie Mellon University, May 1990.

R. Lundgren and A. McMakin, Risk Communication: A Handbook for Communicating Environmental. Safety, and Health Risks, Columbus (Ohio): Battelle Press, 1998.

F. M. Lynn and G. J. Busenbert, "Citizen Advisory Committees and Environmental Policy: What We Know, What's Left to Discover," Risk Analysis, Vol. 15, 1995, pp. 147-162.

D. G. MacGregor, P. Slovic, and M. G. Morgan, "Perception of Risks From Electromagnetic Fields: A Psychometric Evaluation of a Risk-Communication Approach," Risk Analysis, Vol. 14, 1994, pp. 815-828. 
M. Maharik and B. Fischhoff, "The Risks of Using Nuclear Energy Sources in Space: Some Lay Activists' Peceptions," Risk Analysis, Vol. 12, 1992, pp. 383-392.

M. Maharik and B. Fischhoff, "Risk Knowledge and Risk Attitudes Regarding Nuclear Energy Sources in Space," Risk Analysis, Vol. 13, 1993, pp. 345-353.

National Academy of Sciences, The Nuclear Weapons Complex: Management for Health. Safety, and the Environment, Washington, D.C.: National Academy Press, 1990.

P. Nogee and B. Lieberman, "The Auction Value of Certain Risky Situations," Journal of Psychology, Vol. 49, 1960, pp. 167-179.

S. Pepper "Problems in the Quantification of Frequency Expressions," in D. Fiske (editor), New Direction Methodology of Social and Behavioral Sciences: Problems with Language Imprecision, San Francisco: Jossey-Bass, 1981.

E. Peters and P. Slovic, "The Role of Affect and Worldviews as Orienting Dispositions in the Perception and Acceptance of Nuclear Power," Journal of Applied Psychology, Vol. 26, 1996, pp. 1427-1453.

M. G. Preston and P. Baratta, "An Experimental Study of the Auction-Value of an Uncertain Outcome," American Journal of Psychology, Vol. 60, 1948, pp. 183-193.

D. Read, A. Bostrom, M. G. Morgan, B. Fischhoff, and T. Smuts, "What Do People Know About Global Climate Change? Part 2: Survey Studies of Educated Laypeople," Risk Analysis, Vol. 14, 1994, pp. 971-982.

L. M. Reder, "Techniques Available to Author, Teacher, and Reader to Improve Retention of Main Ideas of a Chapter," in S. F. Chipman, J. W. Segal, and J. R. Glaser (editors), Thinking and Learning Skills, Vol. 2 Research and Open Questions, Hillsdale (New Jersey): Lawrence Erlbaum Associates, 1985.

O. Renn, T. Webler, and P. Wiedemann (editors), Fairness and Competence in Citizen Participation: Evaluting Models for Environmental Discourse, Dordrecht (The Netherlands): Kluwer, 1995.

E. A. Rosa and W. R. Freudenburg, "The Historical Development of Public Reactions to Nuclear Power: Implications for Nuclear Waste Policy," in R. E. Dunlap, M. E. Kraft, and E. A. Rosa (editors), Public Reactions to Nuclear Waste, Durham (North Carolina): Duke University Press, 1993.

J. Rosener, "Matching Method to Purpose: The Challenge of Planning Citizen Participation Activities," in S. Langton (editor), Citizen Participation in America, Lexington (Massachusetts): Lexington Books, 1978. 
E. Roth, M. G. Morgan, B. Fischhoff, L. Lave, and A. Bostrom, "What Do We Know About Making Risk Comparisons?", Risk Analysis, Vol. 10, 1990, pp. 375-387.

K. E. Rowan, "Goals, Obstacles, and Strategies in Risk Communication: A Problem-Solving Approach to Improving Communication about Risks," Journal of Applied Communication Research, Vol. 19, 1991, pp. 300-329.

K. E. Rowan, "Strategies for Enhancing Comprehension of Science," in B. V. Lewenstein (editor), When Science Meets The Public, Washington, D.C.: American Association for the Advancement of Science, 1992.

K. E. Rowan, "Why Rules for Risk Communication Are Not Enough: A Problem-Solving Approach to Risk Communication," Risk Analysis, Vol. 14, 1994, pp. 365-374.

S. Shiloh and M. Sagi, "Effect of Framing on the Perception of Genetic Recurrence Risks," American Journal of Medical Genetics, Vol. 33, 1989, pp. 130-135.

J. A. Shymansky and W. C. Kyle, Jr., "A Summary of Research in Science Education - 1986. 2.0 Learning and the Learner," Science Education, Vol. 72, 1988, pp. 276-340.

R. H. Simpson, "The Specific Meanings of Certain Terms Indicating Differing Degrees of Frequency," Quarterly Journal of Speech, Vol. 30, 1944, pp. 328-330.

R. H. Simpson, "Stability in Meanings for Quantitative Terms: A Comparison over 20 Years," Quarterly Journal of Speech, Vol. 49, 1963, pp. 146-151.

P. Slovic, "Perceived Risk, Trust, and Democracy: A Systems Perspective," Risk Analysis, Vol. 13, 1993, pp. 675-682.

P. Slovic, "Trust, Emotion, Sex, Politics, and Science: Surveying the Risk-Assessment Battlefield," in M. H. Bazerman, D. M. Messick, A. E. Tenbrunsel, and K. A. Wade-Benzoni (editors), Environment, Ethics, and Behavior: The Psychology of Environmental Valuation and Degradation, San Francisco: The New Lexington Press, 1997.

P. Slovic, N. Kraus, and V. T. Covello, "What Should We Know About Making Risk Comparisons?", Risk Analysis, Vol. 10, 1990, pp. 389-392.

P. Slovic, M. Layman, and J. H. Flynn, "Perceived Risk, Trust, and Nuclear Waste: Lessons from Yucca Mountain," in R. E. Dunlap, M. E. Kraft, and E. A. Rosa (editors), Public Reactions to Nuclear Waste, Durham (North Carolina): Duke University Press, 1993.

R. C. Sprowls, "Psychological-Mathematical Probability in Relationships of Lottery Gambles," American Journal of Psychology, Vol. 66, 1953, pp. 126-130. 
D. R. Stone and R. J. Johnson, "A Study of Words Indicating Frequency," Journal of Educational Psychology, Vol. 50, 1959, pp. 224-227.

L. Susskind and J. Cruikshank, Breaking the Impasse: Consensual Approaches to Resolving Public Disputes, New York: Basic Books, 1987.

R. D. Tennyson and M. J. Cocchiarella, "An Empirically Based Instructional Design Theory for Teaching Concepts," Review of Educational Research, Vol. 56, 1986, pp. 40-71.

T. S. Wallsten and D. V. Budescu, "A Review of Human Linguistic Probability Processing: General Principles and Empirical Evidence," The Knowledge Engineering Review, Vol. 10, pp. 43-62.

A. E. Waltar, America the Powerless, Madison (Wisconsin): Cogito Books, 1995.

T. F. Yosie and T. D. Herbst, Using Stakeholder Processes in Environmental Decisionmaking: An Evaluation of Lessons Learned, Key Issues, and Future Challenges, http://www.riskworld.com/Nreports/nr5me001.htm, 1998. 